\title{
MATHEMATICAL DESCRIPTION HYDRODYNAMICS OF HIGH-PERFORMANCE DUST AND GAS TREATMENT EQUIPMENT
}

\author{
МАТЕМАТИЧНИЙ ОПИС ГІДРОДИНАМІКИ \\ ВИСОКОЕФЕКТИВНОГО ПИЛОГАЗООЧИСНОГО АПАРАТУ
}

\author{
Ivan S. Kozii \\ i.koziy@ecolog.sumdu.edu.ua \\ ORCID: 0000-0003-0402-6876 \\ Leonid D. Plyatsuk \\ 1.plyacuk@ecolog.sumdu.edu.ua \\ ORCID: 0000-0003-0095-5846 \\ Larisa L. Hurets \\ 1.gurets@ecolog.sumdu.edu.ua \\ ORCID: 0000-0002-2318-4223
}

\author{
I. С. Козій, \\ канд. техн. наук, доцент, \\ докторант \\ Л. Д. Пляцук, \\ докт. техн. наук, професор \\ Л. Л. Гурець, \\ докт. техн. наук, доцент
}

\author{
Sumy State University, Sumy \\ Сумський державний університет, Суми
}

\begin{abstract}
Purpose. The aim of the study is the physical and mathematical description of the mechanisms of the process of capturing fine dust in a equipment with an on-load tap changer due to the mechanism of condensation and coagulation growth of aerosol particles.

Method. The authors analyzed information sources and regulations Theoretical hydrodynamics for mathematical description condensation and coagulation mechanism enlargement of aerosol particles in the test device. The object of research is to study the hydrodynamics of a highly efficient dust and gas cleaning device. The subject of the study is the regularities of condensation and coagulation mechanism of particle aggregation.

Results. As a result of mathematical dependences, the system of differential and integral-differential equations is obtained, which allow to describe the process of aggregation of aerosol particles due to condensation and coagulation growth and, as a result, calculate the efficiency of fog and other aerosols in high-intensity dust and gas cleaning device. The physical and mathematical picture of interaction of dust-gas flow with vapor-liquid mixture - condensation mechanism of aerosol particles aggregation in the device are considered. The mechanism of formation and mathematical description of the vortex flow during the passage of cylindrical elements - the coagulation mechanism of growth of aerosol particles in the device are considered.

Scientific novelty. First obtained system of differential and integral-differential equations to describe the process of enlargement aerosol particles in the investigated device type.

Practical importance. The enlargement of aerosol particles in the first zone of the device is due to the mechanism of condensation, as well as turbulent and Brownian coagulation, which allows to determine the further possibility of trapping particles due to inertial or turbulent diffusion mechanism.
\end{abstract}

Key words: environment; dust and gas emissions; high-performance equipment; aerosols; vortex flows.

Анотація. Мета. Метою роботи є опис фізичної картини поведінки пилогазового потоку та математичне моделювання гідродинаміки високоефективного апарату з регулярною пульсаційною насадкою за рахунок механізму конденсаційного та коагуляційного зростання частинок аерозолю.

Методика. Авторами проведено аналіз інформаційних джерел та положень теоретичної гідродинаміки для математичного опису конденсаційного та коагуляційного механізму укрупнення аерозольних часток в досліджуваному апараті. Об'єктом дослідження є вивчення гідродинаміки високоефективного пилогазоочисного апарату. Предметом дослідження є закономірності конденсаційного та коагуляційного механізму укрупнення часток.

Результати. В результаті аналізу математичних залежностей в роботі отримано систему диференційних та інтегрально-диференційних рівнянь, які дозволяють описати процес укрупнення аерозольних частинок за 
рахунок конденсаційного та коагуляційного зростання і, як підсумок, виконувати розрахунок ефективності вловлення туманів та інших аерозолів в високоінтенсивному пилогазоочисному апараті. Розглянуто фізичну та математичну картину взаємодії пилогазового потоку з парорідинною сумішшю - конденсаційний механізм укрупнення аерозольних часток в апараті. Розглянуто механізм утворення і математичний опис вихрового потоку при проходженні циліндричних елементів - коагуляційний механізм зростання аерозольних частинок в апараті.

Наукова новизна. Вперше отримано систему диференційних та інтегрально-диференційних рівнянь, які дозволяють описати процес укрупнення аерозольних частинок в апараті досліджуваного типу.

Практична значимість. Укрупнення аерозольних частинок в першій зоні апарату відбувається за рахунок механізму конденсаційного зростання, а також турбулентної і броунівський коагуляції, що дозволяє визначити подальшу можливість уловлювання частинок за рахунок інерційного або турбулентному-дифузійного механізму. Ключові слова: навколишнє середовище; пилогазові викиди; високоефективний апарат; аерозолі; вихрові потоки.

\section{ПОСТАНОВКА ЗАДАЧІ}

Важливим питанням сьогодення $є$ екологічні проблеми атмосфери, що забруднюється викидами газу 3 дрібнодисперсними твердими частинками (аерозолями), на різноманітних промислових об'єктах. Осадження забруднюючих речовин $з$ газових викидів промислових підприємств призводить до забруднення грунту і міграції важких металів в підземні і поверхневі води $[1 ; 2]$.

Це ставить завдання розробки природоохоронних заходів з охорони атмосферного повітря від різноманітних за складом і фізико-хімічними властивостями викидів промислових підприємств [3; 4]. Одним із шляхів зниження кількості пилогазових викидів є підвищення ефективності газоочисного устаткування. Вибір газоочисного устаткування повинен враховувати цілий ряд факторів: фізико-хімічні характеристики газу-носія, характеристики хімічних і твердих забруднюючих речовин [5-7]. Комплексне очищення газів від газоподібних речовин і твердих частинок вимагає застосування багатоступеневих систем очищення, що, як правило, збільшує капітальні та експлуатаційні витрати [8; 9].

Тому задача підбору високоефективного і надійного обладнання, здатного вловлювати дрібнодисперсний пил, є достатньо актуальною.

\section{АНАЛІЗ ОСТАННІХ ДОСЛІДЖЕНЬ І ПУБЛІКАЦІЙ}

Сучасний розвиток виробництва і технологій супроводжується надходженням у навколишнє середовище великої кількості різноманітних аерозольних систем (тумани, дим, дрібнодисперсний пил та інше) [10]. Існуюче надходження аерозолів в навколишнє середовище характеризується довготривалим часом існування, демонструє високий ступінь забрудненості і широке розповсюдження на великі відстані [11], що говорить про значний регіональний і глобальний аспекти впливу на довкілля.

Зростаючий науковий інтерес до забруднення повітряного середовища аерозольними частками пояснюється їх важливим значенням для екологічної безпеки. Фактично тверді частинки $є$ однією
3 найскладніших проблем, що впливають на якість повітря, так і для досліджень в напрямку зміни клімату [12]. Актуальність роботи підтверджується аналізом бази даних Scopus за напрямком досліджень - викиди аерозолів у хімічній промисловості, який вказує на те, що кількість наукових публікацій збільшилась у понад десять разів за останні 10 років.

\section{ВІДОКРЕМЛЕННЯ НЕ ВИРІШЕНИХ РАНІШЕ ЧАСТИН ЗАГАЛЬНОЇ ПРОБЛЕМИ}

Звичайне обладнання для видалення твердих часток (електрофільтри, циклони та інші) не дуже ефективне для дрібнодисперсних частинок $з$ розмірами менше мікрону. Одним із шляхів інтенсифікації інерційно-дифузійних процесів осадження, що становлять основу технології «мокрого» очищення газів від аерозолів (туману, пилу, диму та інші), є проведення цих процесів в інтенсивних режимах розвинутої турбулентності. Їх реалізація можлива в апаратах з регулярною пульсаційною насадкою (РПН).

\section{МЕТА ДОСЛІДЖЕННЯ}

Метою роботи є опис фізичної картини поведінки пилогазового потоку та математичне моделювання гідродинаміки апарату з РПН за рахунок механізму конденсаційного та коагуляційного зростання частинок аерозолю.

\section{МЕТОДИ, ОБ'СКТ ТА ПРЕДМЕТ ДОСЛІДЖЕННЯ}

Під час дослідження були використані такі наукові методи:

- метод аналізу інформаційних джерел стосовно використання апаратів та устаткування для очистки газів;

- засади теоретичної гідродинаміки для математичного розрахунку конденсаційного та коагуляційного механізму укрупнення аерозольних часток в досліджуваному апараті з РПН.

Об'єктом дослідження є вивчення гідродинаміки високоефективного пилогазоочисного апарату.

Предметом дослідження є закономірності конденсаційного та коагуляційного механізму укрупнення аерозольних часток в апараті з РПН. 


\section{ТЕХНОЛОГІЇ ЗАХИСТУ НАВКОЛИШНЬОГО СЕРЕДОВИЩА № 1 п 2021}

\section{ОСНОВНИЙ МАТЕРІАЛ}

Для опису гідродинаміки апарата з РПН було використано лабораторний стенд, що становить собою прямоточний апарат колонного типу з регулярним розташуванням турбулізуючих елементів (див. рис. 1).

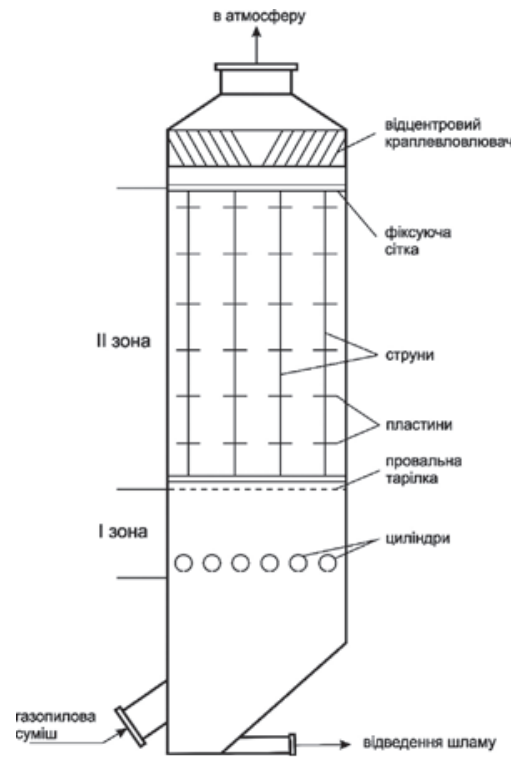

Рис. 1. Схема прямоточного апарату 3 регулярним розташуванням турбулізуючих елементів

Контактна зона апарату складається із двох послідовно з'єднаних зон обробки газів. У першій зоні відбувається укрупнення зважених у газовому потоці аерозольних часток за рахунок конденсаційнокоагуляційного механізму осадження. Вона складається із пакета плоскопаралельних каналів з рівномірно розташованими в них турбулізуючими елементами, що виконані у вигляді порожніх циліндрів. Циліндри у нижній частині мають перфорацію і одночасно виконують функцію парових каналів (подається парорідинна суміш). Друга зона становить собою шар насадки у вигляді регулярно розміщених по перетину струн із рівномірно закріпленими на них пластинами.

Розглянемо більш детально поведінку пилогазового потоку в І зоні апарата.

Рух аерозольних частинок після обтікання тіла відбувається 3 коливаннями і пульсаціями, які характерні для відривної течії несучого (газового) потоку. Крім того, під час руху полідисперсного аерозолю в зоні одиничного вихору характерний перерозподіл фракцій аерозолю в об'ємі вихору. Так, крупна фракція частинок, що володіє інерцією, прагне під дією відцентрових сил до периферії вихору, а безінерційна дрібнодисперсна фракція обертається у осьовій зоні вихору. Таким чином, вихрова течія потоку і його відривний (пульсаційний) характер руху значною мірою сприяе інтенсифікації процесів укрупнення і осадження частинок аерозолів.

Під час переходу до розгляду руху потоку в одиночному вихорі $з$ позицій теоретичної гідродинаміки припустимо, що вихор складається із ядра вихору і поля вихору, які обертаються за законом твердого тіла (див. рис. 2).

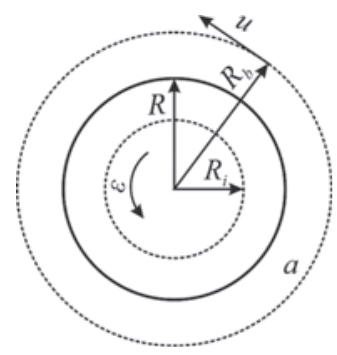

Рис. 2. Схематичне зображення ядра і поля вихору

Тоді для вимірювання лінійної швидкості руху від радіусу вихору можна записати:

для ядра вихору $\left(R_{i}<R\right)$

$$
\int_{S} u_{i} d S^{(a)}=\omega \pi R_{i}^{2},
$$

для поля вихору $\left(R_{b}>R\right)$

$$
\int_{S} u d S^{(a)}=\omega \pi R^{3} .
$$

Тут $S$ - площа перетину вихору, ${ }^{2} ; \omega-$ кутова швидкість руху, $\mathrm{c}^{-1}$. Так як $u$ та $u_{i}$ сталі на відповідних колах вихору, то запишемо співвідношення:

для ядра вихору

$$
2 \pi R_{i} u_{i}=\omega \pi R_{i}^{2},
$$

для поля вихору

$$
2 \pi R_{b} u=\omega \pi R^{2} .
$$

Звідси випливає, що для ядра вихору

$$
u_{i}=\frac{\omega R_{i}}{2},
$$

для поля вихору

$$
u=\frac{\omega R}{2 R_{b}} .
$$

Якщо у рівняння (5) і (6) підставити значення кутової швидкості, що дорівнює

$$
\omega=\frac{\Gamma}{\pi R^{2}},
$$

де $\Gamma=\frac{u_{\mathrm{g}}^{2}}{2 f_{b}}=\frac{u_{\mathrm{g}} d_{c}}{2 S h}-$ інтенсивність циркуляції швидкості, $\mathrm{m}^{2} / \mathrm{c} ; f_{b}$ - частота зриву вихорів, $\mathrm{c}^{-1} ; S h-$ число Струхаля, то можна отримати наступні залежності:

для ядра вихору

$$
u_{i}=\frac{\Gamma R_{i}}{2 \pi R^{2}},
$$

для поля вихору

$$
u=\frac{\Gamma}{2 \pi R_{b}} .
$$

На основі закону зміни лінійної швидкості потоку за радіусом вихору визначимо перепад тисків і температур в ядрі і полі вихору. 
Закон збереження імпульсу в циліндричних координатах можна записати у вигляді:

$$
\rho \frac{u}{R}=\frac{\partial P}{\partial R} \text {. }
$$

Підставимо у рівняння (10) значення лінійної швидкості із рівняння (8) та (9) і проінтегруємо за тиском від $P_{0}$ до $P$, а також за радіусом вихору від 0 до $R$. Отримаємо:

$$
P_{\mathrm{g}}=\frac{\Gamma^{2} R^{2} \rho_{\mathrm{g}}}{8 \pi^{2} R_{b}^{4}}+P_{0}
$$

де $P_{0}-$ тиск в центрі вихору, $P_{\mathrm{g}}-$ тиск газу, Па. Тоді для поля вихору залежність буде мати вигляд

$$
P_{\mathrm{R}}=P_{\mathrm{g}}-\frac{\Gamma^{2} \rho_{\mathrm{g}}}{8 \pi^{2} R_{b}^{2}} .
$$

Для $P_{0}$ можна записати вираз

$$
P_{o}=P_{\mathrm{g}}-\frac{\Gamma^{2} \rho_{\mathrm{g}}}{4 \pi^{2} R_{b}^{2}},
$$

а для вихору буде записано наступне співвідношення:

$$
P_{R^{*}}=P_{\mathrm{g}}-\frac{\Gamma^{2} \rho_{\mathrm{g}}}{4 \pi^{2} R_{b}^{2}}\left(1-\frac{R_{*}^{2}}{2 R_{b}^{2}}\right) .
$$

У підсумку для парогазового потоку, що обтікає циліндр 3 діаметром $d_{c}$, перепад тисків в одиночному вихорі можна записати:

для ядра вихору

$$
P_{R^{*}}=P_{\mathrm{g}}-\rho_{\mathrm{g}}\left(\frac{u_{\mathrm{g}} d_{c}}{4 \pi R_{b} S h}\right)^{2}\left(1-\frac{R_{*}^{2}}{2 R_{b}^{2}}\right),
$$

для поля вихору

$$
P_{R}=P_{\mathrm{g}}-\frac{\rho_{\mathrm{g}}}{8}\left(\frac{u_{\mathrm{g}} d_{c}}{4 \pi R_{b} S h}\right)^{2} .
$$

У випадку адіабатичної течії парогазової суміші аналогічний розв'язок спільно з рівнянням адіабати дозволить отримати наступні перепади тисків:

$$
\begin{gathered}
\Delta P_{R^{*}}=\frac{k-1}{k} \rho_{\mathrm{g}}\left(\frac{u_{\mathrm{g}} d_{c}}{4 \pi R_{b} S h}\right)^{2}\left(1-\frac{R_{*}^{2}}{2 R_{b}^{2}}\right), \\
\Delta P_{R}=\frac{k-1}{k} \frac{\rho_{\mathrm{g}}}{8}\left(\frac{u_{\mathrm{g}} d_{c}}{4 \pi R_{b} S h}\right)^{2},
\end{gathered}
$$

де $k$ - показник адіабати.

Для того щоб отримати залежності за змінами температур парогазової суміші в одиночному вихорі розв'яжемо рівняння (17) та (18) сумісно з рівнянням стану ідеального газу $P V=R_{\mathrm{g}} T$. Тоді отримаємо:

для ядра

$$
\Delta T_{R^{*}}=\frac{k-1}{k} \frac{1}{R_{\mathrm{g}}}\left(\frac{u_{\mathrm{g}} d_{c}}{4 \pi R_{b} S h}\right)^{2}\left(1-\frac{R_{*}^{2}}{2 R_{b}^{2}}\right),
$$

для поля

$$
\Delta T_{R}=\frac{k-1}{k} \frac{1}{2 R_{\mathrm{g}}}\left(\frac{u_{\mathrm{g}} d_{c}}{4 \pi R_{b} S h}\right)^{2} .
$$

У рівняннях (17) - (20) числове значення радіусу вихору $R_{b}$ і ядра вихору $R^{*}$ можна визначити за формулами:

$$
\begin{gathered}
R_{b}=0,25 d_{c}, \\
R^{*}=\left(5,04 v_{\mathrm{g}} \tau_{b}\right)^{1 / 2},
\end{gathered}
$$

де $\tau_{b}$ - час формування вихору, c; $v_{\mathrm{g}}$ - коефіцієнт кіне-

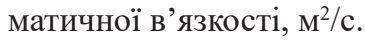

Початок утворення кожного вихору, що зривається з циліндру, очевидно, має відношення до вісі циліндра, тоді для часу формування вихору можна записати:

$$
\tau_{b}=0,5 d_{c} / u_{b} .
$$

Тут $u_{b}=0,86 u_{\mathrm{g}}-$ швидкість руху вихору, м/с.

За умов широких меж розповсюдження аерозольних частинок за розмірами внаслідок дії відцентрових сил, відбувається фракційний перерозподіл частинок за радіусом вихору. При цьому більш крупні частинки видаляються із зони вихору у суцільний потік, а дрібніші обертаються у вихорі.

Детальний розрахунок структури такого двофазного потоку пов'язаний із значними складнощами, оскільки необхідно визначити траєкторію частинок як у середині вихорів, так і за їх межами. Однак, у нашому випадку, 3 певними припущеннями можна обмежитися знаходженням певного критичного радіусу аерозольних частинок $r_{k r}$, який буде певною мірою частиною одиниць аерозолю, що обертається у вихорі і залишає його за час, рівний часу формування вихору $\tau_{b}$.

Для опису процесу руху частинок у вихорі можна скористатися рівнянням

$$
\frac{d^{2} x}{d t^{2}}+\frac{1}{A} \frac{d x}{d t}-\frac{1}{x^{3}}=0,
$$

де $x=R / R_{b} ; t=\tau u_{p . t} / R_{b}-$ безрозмірні величини; $u_{p . t}-$ тангенціальна швидкість частинки, м/c;

$$
A=\frac{r_{p}\left(\rho_{p}-\rho_{\mathrm{g}}\right) u_{p . t}}{72 \mu_{\mathrm{g}} R_{b}} .
$$

Залежність (24) являє собою нелінійне диференційне рівняння, яке не може бути розв'язане у аналітичний спосіб. Однак, якщо знехтувати диференціалом вторинного порядку (через його мізерність), розділити змінні і проінтегрувати за t від 0 до t та за $\mathrm{x}$ від $\mathrm{x}_{1}$ до $\mathrm{x}_{2}$, а потім замінити безрозмірні величини, підставити значення $u_{p . t}=u_{\mathrm{g}}$, що розраховується за рівнянням (8), отримаємо формулу розрахунку критичного радіусу частинок для ядра вихору:

$$
r_{k r}=70 S h\left[\left(\frac{\mu_{\mathrm{g}}}{\rho_{c}-\rho_{\mathrm{g}}}\right)\left(1-\frac{R^{2}}{R^{* 2}}\right) \frac{1}{u_{\mathrm{g}} d_{c}}\right]^{1 / 2} \frac{R^{* 3}}{R} .
$$

Для поля вихору, враховуючи, що $R_{b}>R^{*}$ і рівняння (9), вираз можна записати у наступному вигляді: 


\section{ТЕХНОЛОГІЇ ЗАХИСТУ НАВКОЛИШНЬОГО СЕРЕДОВИЩА № 1-2021}

$$
r_{k r}=4,08 S h\left(\frac{\mu_{\mathrm{g}}}{\rho_{c}-\rho_{\mathrm{g}}}\right)^{1 / 2}\left(\frac{d_{c}}{u_{\mathrm{g}}}\right)^{1 / 2} .
$$

Згідно з рівнянням (20), для нев'язких газів немає необхідності проводити розрахунок збільшення частинок у ядрі вихору, оскільки для таких середовищ $R_{b}>R^{*} \mathrm{i}$, як наслідок, вагова частка аерозолю в ядрі мізерно мала. Тоді залежність функції розподілу частинок за розмірами від часу за рахунок конденсації буде мати вигляд:

для суцільного потоку $\left(r^{\prime}>r_{k r}\right)$

$$
\frac{\partial f\left(r^{\prime}, \tau\right)}{\partial \tau}=-\frac{\partial}{\partial r^{\prime}}\left[f\left(r^{\prime}, \tau\right) \frac{d r^{\prime}}{d \tau}\right],
$$

для вихрового потоку $\left(r^{\prime \prime}<r_{k r}\right)$

$$
\frac{\partial f\left(r^{\prime \prime}, \tau\right)}{\partial \tau}=-\frac{\partial}{\partial r^{\prime \prime}}\left[f\left(r^{\prime \prime}, \tau\right) \frac{d r^{\prime \prime}}{d \tau}\right],
$$

де $r^{\prime}$ та $r^{\prime \prime}$ - поточні радіуси частинок у суцільному і вихровому потоці відповідно.

Процес укрупнення аерозольних частинок в об'ємі комірки за рахунок гетерогенної конденсації пари, як зазначалося вище, не є єдиним механізмом, що забезпечує зростання частинок. Наявність турбулентних пульсацій і броунівського (теплового) руху частинок також призводить до їх коагуляційного зростання. 3 урахуванням цих аргументів рівняння балансу розподілу частинок, що відображує зміну функції розподілу частинок за розмірами в часі, які в подальшому зазнають конденсаційного і коагуляційного зростання, має такий вигляд:

$$
\begin{aligned}
& \frac{\partial f\left(r_{p}, \tau\right)}{\partial \tau}+\frac{\partial}{\partial r}\left[f\left(r_{p}, \tau\right) \frac{d r}{d \tau}\right]=\int_{r=0}^{r=r_{r} / \sqrt[3]{2}} K_{\kappa}\left(\sqrt[3]{r_{p}^{3}-r^{3}}, r\right) \cdot f\left(\sqrt[3]{r_{p}^{3}-r^{3}}, \tau\right) \times \\
& f(r, \tau) \cdot\left(\frac{r}{\left(\sqrt[3]{r_{p}^{3}-r^{3}}\right)}\right)^{2} d r-\int_{r=0}^{r=0} K_{k}\left(r_{p}, \tau\right) \cdot f\left(r_{p}, \tau\right) \cdot f(r, \tau) d r+ \\
& +\frac{Q}{V_{c}}[f(r, 0)-f(r, \tau)]
\end{aligned}
$$

де $r$ - поточний радіус аерозольної частинки, м; $Q$ - витрата аерозолю, $\mathrm{M}^{3} / \mathrm{c} ; V_{\mathrm{c}}-$ об'єм комірки, $\mathrm{M}^{3}$; $K_{\kappa}$ - коефіцієнт коагуляції за рахунок турбулентного та броунівського механізмів, $\mathrm{m}^{3} / \mathrm{c}$.

Коефіцієнт коагуляції $K_{k}$, що входить до рівняння (29), являє собою суму коефіцієнтів турбулентної $K_{\mathrm{r}}$ і броунівської $K_{b}$ коагуляцій:

$$
K_{\kappa}=K_{\mathrm{T}}+K_{b} .
$$

$K_{b}$ можна визначити із співвідношення

$$
K_{b}=\frac{4 k_{b} T_{\mathrm{g}}}{3 \mu_{\mathrm{g}}},
$$

де $k_{\tilde{\sigma}}$ - стала Больцмана.
Коефіцієнт турбулентної коагуляції згідно [8] дорівнює:

$$
K_{\mathrm{T}}=1,67\left(r_{p}+r\right)^{3} \sqrt{\frac{E}{v_{\mathrm{g}}}} .
$$

Дисипацію енергії в об'ємі комірки $E$ визначимо, як

$$
E=\frac{N_{b}}{V_{c} \rho_{\mathrm{pg}}},
$$

де $N_{b}$ - потужність вихору, що утворюється під час обтікання циліндру суцільним потоком.

Потужність вихору визначаємо за рівнянням

$$
N_{b}=C_{L} \sqrt{\frac{C_{L}}{C_{D}}} \rho_{\mathrm{pg}} l_{c} d_{c} \frac{u_{\mathrm{g}}^{3}}{2},
$$

де $C_{L}$ - коефіцієнт підйомної сили; $C_{D}$ - коефіцієнт опору; $u_{\mathrm{g}}$ - дійсна швидкість газового потоку, м/с; $l_{\mathrm{c}}-$ довжина циліндру, м.

Об'єм комірки

$$
V_{c}=b l_{c} t_{h c},
$$

де $b$ - ширина плоскопаралельного каналу, м; $t_{h c}$ - висота комірки, що дорівнює відстані між вісями циліндрів, м.

Підставивши рівняння (34) і (35) у рівняння (33), отримуємо

$$
\begin{aligned}
& E=\frac{C_{L D}}{2 b} \frac{d_{c}}{t_{h c}} u_{\mathrm{g}}^{3}, \\
& \text { де } C_{L D}=C_{L} \sqrt{\frac{C_{L}}{C_{D}}} .
\end{aligned}
$$

\section{ОБГОВОРЕННЯ ОТРИМАНИХ РЕЗУЛЬТАТІВ}

Таким чином, у результаті аналізу математичних залежностей у роботі отримано систему диференційних та інтегрально-диференційних рівнянь, які дозволяють описати процес укрупнення аерозольних частинок за рахунок конденсаційного та коагуляційного зростання i, як підсумок, виконувати розрахунок ефективності вловлення туманів та інших аерозолів у високоінтенсивних апаратах з РПН.

\section{ВИСНОВКИ}

1. У роботі розглянуто фізичну та математичну картину взаємодії пилогазового потоку з парорідинною сумішшю - конденсаційний механізм укрупнення аерозольних часток в апараті.

2. Розглянуто механізм утворення і математичний опис вихрового потоку під час проходження циліндричних елементів, які реалізують коагуляційний механізм зростання аерозольних частинок в апараті.

3. Зроблено висновок про можливість використання апаратів з РПН для комплексної очистки пилогазових викидів промислових виробництв.

\section{REFERENCES}

[1] Abdul-Wahab, S.A., Jupp, B.P. (2009). Levels of heavy metals in subtidal sediments in the vicinity of thermal power/ desalination plants: a case study. Desalination, vol. 244, pp. 261-282. 
[2] Raja, R., Nayak, A.K., Shukla, A.K., Rao, K.S. (2015). Impairment of soil health due to fly ash-fugitive dust deposition from coal-fired thermal power plants. Environmental Monitoring and Assessment, vol. 187, p. 679.

[3] Xiping, W., Lei, D. (2016). Study on carbon capture and storage (CCS) investment decision-making based on real options for China's coal-fired power plants. Journal of Cleaner Production, vol. 112, no. 5, pp. 4123-4131.

[4] Tronvil, P. (2008). Developing standards: Global standards for air cleaning equipment. Filtration \& Separation, vol. 45, no. 9 , pp. 28-31.

[5] Phillips, H.W. (2000). Select the proper gas cleaning equipment. Chemical Engineering Progress, vol. 96, no. 9, pp. 19-38.

[6] Hession, M. (1997). Incinerator and gas cleaning equipment overview. Health Estate J., vol.51, no. 8, pp. 6-7.

[7] Sutherland, K. (2007). Chooing equipment: Cleaning air and gas. Filtration \& Separation, vol. 44, no. 1, pp. 16-19.

[8] Ladygichev, M.G., Berner, G.YA. (2004). Zarubezhnoye i otechestvennoye oborudovaniye dlya ochistki gazov: Spravochnoye izdaniye [Foreign and domestic gas purification equipment: Reference publication]. Moscow: Teplotekhnik - Heat engineer, 2004. 696 p. [in Russian]

[9] Straus, V. (1981). Promyshlennaya ochistka gazov [Industrial gas cleaning]. - Moscow: Khimiya - Chemistry, 1981. 616 p. [in Russian]

[10] Butler, T.M., Lawrence, M.G. (2009). The influence of megacities on global atmospheric chemistry: A modelling study. Environ. Chem., vol. 6(3), pp. 219-225.

[11] Hallquist, M., Wenger, J., Baltensperger, U., Rudich, Y., Simpson, D., Claeys, M., Dommen, J., Donahue, N., George, C., Goldstein, A. (2009). The formation, properties and impact of secondary organic aerosol: current and emerging issues. Atmospheric Chemistry and Physics, vol. 9, pp. 5155-5236. DOI: 10.5194/acp-9-5155-2009.

[12] Kahn, R., Yu, H., Schwartz, S., Chin, M., Feingold, G., Remer, L., Rind, D., Halthore, R., DeCola, P. (2009). Atmospheric Aerosol Properties and Climate Impacts. National Aeronautics and Space Administration: Washington, DC, USA.

\section{СПИСОК ВИКОРИСТАНОЇ ЛІТЕРАТУРИ}

[1] Abdul-Wahab, S.A., Jupp, B.P. (2009). Levels of heavy metals in subtidal sediments in the vicinity of thermal power/ desalination plants: a case study. Desalination, vol. 244, pp. 261-282.

[2] Raja, R., Nayak, A.K., Shukla, A.K., Rao, K.S. (2015). Impairment of soil health due to fly ash-fugitive dust deposition from coal-fired thermal power plants. Environmental Monitoring and Assessment, vol. 187, p. 679.

[3] Xiping, W., Lei, D. (2016). Study on carbon capture and storage (CCS) investment decision-making based on real options for China's coal-fired power plants. Journal of Cleaner Production, vol. 112, no. 5, pp. 4123-4131.

[4] Tronvil, P. (2008). Developing standards: Global standards for air cleaning equipment. Filtration \& Separation, vol. 45, no. 9 , pp. 28-31.

[5] Phillips, H.W. (2000). Select the proper gas cleaning equipment. Chemical Engineering Progress, vol. 96, no. 9, pp. 19-38.

[6] Hession, M. (1997). Incinerator and gas cleaning equipment overview. Health Estate J., vol.51, no. 8, pp. 6-7.

[7] Sutherland, K. (2007). Chooing equipment: Cleaning air and gas. Filtration \& Separation, vol. 44, no. 1, pp. 16-19.

[8] Ладыгичев, М.Г., Бернер, Г.Я. (2004). Зарубежное и отечественное оборудование для очистки газов: Справочное издание. Москва : Теплотехник, $696 \mathrm{c}$.

[9] Страус, В. (1981). Промышленная очистка газов. Москва : Химия. 616 с.

[10] Butler, T.M., Lawrence, M.G. (2009). The influence of megacities on global atmospheric chemistry: A modelling study. Environ. Chem., vol. 6(3), pp. 219-225.

[11] Hallquist, M., Wenger, J., Baltensperger, U., Rudich, Y., Simpson, D., Claeys, M., Dommen, J., Donahue, N., George, C., Goldstein, A. (2009). The formation, properties and impact of secondary organic aerosol: current and emerging issues. Atmospheric Chemistry and Physics, vol. 9, pp. 5155-5236. DOI: 10.5194/acp-9-5155-2009.

[12] Kahn, R., Yu, H., Schwartz, S., Chin, M., Feingold, G., Remer, L., Rind, D., Halthore, R., DeCola, P. (2009). Atmospheric Aerosol Properties and Climate Impacts. National Aeronautics and Space Administration: Washington, DC, USA. 